\title{
Kinetics and Mechanism of Oxidation of Leucine and Alanine by Ag(III) Complex in Alkaline Medium
}

\author{
Changying Song, ${ }^{1}$ Lei Chen, ${ }^{2}$ and Jinhuan Shan ${ }^{1}$ \\ ${ }^{1}$ Key Laboratory of Analytical Science and Technology of Hebei Province, College of Chemistry and Environmental Science, \\ Hebei University, Hebei Province, Baoding 071002, China \\ ${ }^{2}$ College of Electronic and Information Engineering, Hebei University, Baoding 071002, China
}

Correspondence should be addressed to Changying Song, songchangyinger@yahoo.com.cn

Received 7 July 2008; Accepted 21 August 2008

Recommended by Tai Lau

Kinetics and mechanism of oxidation of leucine and alanine by $\mathrm{Ag}$ (III) complex were studied spectrophotometrically in alkaline medium at constant ion strength. The reaction was in first order with respect to $\mathrm{Ag}(\mathrm{III}) \mathrm{complex}$ and amino acids (leucine, alanine). The second-order rate constant, $k$, decreased with the increasing in $\left[\mathrm{OH}^{-}\right]$and $\left[\mathrm{IO}_{4}^{-}\right]$. A plausible mechanism was proposed from the kinetics study, and the rate equations derived from mechanism can explain all experimental phenomena. The activation parameters were calculated at $298.2 \mathrm{~K}$.

Copyright (C) 2008 Changying Song et al. This is an open access article distributed under the Creative Commons Attribution License, which permits unrestricted use, distribution, and reproduction in any medium, provided the original work is properly cited.

\section{Introduction}

Transition metals in a higher oxidation state can be stabilized by chelation with suitable polydentate ligands, such as diperiodatargentate(III) [1-4], [ethylenebis(biguanide)silver(III)] $[5,6]$. These complexes were stable in a suitable aqueous solution. $\mathrm{Ag}$ (III) complexes were stabilized in alkaline medium by periodate or tellurate ions $[7,8]$. These complexes such as $\mathrm{Ag}(\mathrm{III}), \mathrm{Cu}(\mathrm{III})$, and $\mathrm{Ni}(\mathrm{IV})$ complex can be used as an oxidation reagents in organic chemistry and analytical chemistry [9-11]. As a kind of oxidation reagents, those complexes have been used widely in kinetic study [12].

The kinetics and mechanism of oxidation of some amino acids have been studied by some researchers. However, the mechanism is different in the different reaction systems [1323]. In order to perfect the mechanism of oxidation of amino acids, the kinetics and mechanism of oxidation of alanine and leucine by $\left[\mathrm{Ag}\left(\mathrm{HIO}_{6}\right)_{2}\right]^{5-}$ have been studied in this paper.

\section{Experimental}

All the reagents used were of A.R. grade. All solutions were prepared with doubly distilled water. Solution of
$\left[\mathrm{Ag}\left(\mathrm{HIO}_{6}\right)_{2}\right]^{5-}$ (DPA) was prepared and standardized by the method reported earlier $[7,8]$. Solution of DPA was always freshly prepared before used.

2.1. Apparatus and Kinetics Measurements and Product Analysis. All kinetics measurements were carried out as previously [12]. The way for product analysis was similar to previous study [24]. After completion of the reaction, the products of oxidation were identified as ammonia and the corresponding ketone by their characteristic spot test [25].

\section{Result and Discussion}

3.1. Kinetics. The pseudo-first-order rate constants $k_{\mathrm{obs}}$ were calculated by the method as previously [12].

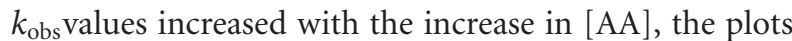
of $k_{\text {obs }}$ versus [AA] are straight line which pass the grid origin at different temperatures (Table 1), the order with respect to $[\mathrm{AA}]$ was unity. Thus, an overall second-order rate law described by (1) is established here, where $k^{\prime}$ represents observed second-order rate constant:

$$
r=k_{\mathrm{obs}}[\mathrm{Ag}(\mathrm{III})]=k^{\prime}[\mathrm{Ag}(\mathrm{III})][\mathrm{AA}] .
$$


TABLE 1: $k_{\text {obs }}$ varied with different $[\mathrm{AA}]$ at different temperatures.

\begin{tabular}{|c|c|c|c|c|c|}
\hline$[\mathrm{AA}] /(\mathrm{mol} / \mathrm{L})$ & 0.01 & 0.02 & 0.03 & 0.04 & 0.05 \\
\hline $\mathrm{T} /(\mathrm{K})$ & \multicolumn{5}{|c|}{$10^{3} k_{\mathrm{obs}} /\left(\mathrm{s}^{-1}\right)$ for oxidation of leucine } \\
\hline 298.2 & 2.740 & 5.360 & 7.789 & 10.17 & 13.69 \\
\hline 303.2 & 4.066 & 7.973 & 11.29 & 15.92 & 19.64 \\
\hline 308.2 & 6.775 & 12.04 & 18.18 & 24.62 & 31.11 \\
\hline \multirow[t]{2}{*}{313.2} & 8.258 & 15.25 & 22.50 & 32.40 & 38.30 \\
\hline & \multicolumn{5}{|c|}{$10^{3} k_{\text {obs }} /\left(\mathrm{s}^{-1}\right)$ for oxidation of alanine } \\
\hline 298.2 & 5.872 & 10.37 & 15.87 & 22.14 & 29.05 \\
\hline 303.2 & 8.671 & 14.38 & 23.24 & 31.97 & 40.89 \\
\hline 308.2 & 12.47 & 22.52 & 33.46 & 44.47 & 59.78 \\
\hline 313.2 & 17.71 & 32.76 & 47.18 & 65.98 & 93.53 \\
\hline
\end{tabular}

$[\mathrm{Ag}(\mathrm{III})]=2.965 \times 10^{-5} \mathrm{~mol} / \mathrm{L},\left[\mathrm{OH}^{-}\right]=0.06 \mathrm{~mol} / \mathrm{L},\left[\mathrm{IO}_{4}{ }^{-}\right]=5.00 \times 10^{-4} \mathrm{~mol} / \mathrm{L}, \mu=0.15 \mathrm{~mol} / \mathrm{L}$.

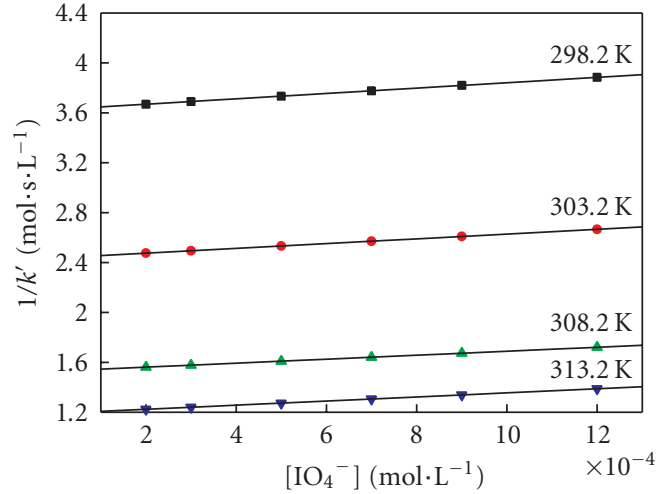

Figure 1: The second-order rate constant, $k^{\prime}$, as a function of the concentration of $\mathrm{IO}_{4}{ }^{-}$at different temperatures for oxidation of leucine.

$k^{\prime}$ values decreased with the increase in $\left[\mathrm{IO}_{4}^{-}\right]$. The plot of $1 / k^{\prime}$ versus $\left[\mathrm{IO}_{4}{ }^{-}\right]$was a straight line (Figures 1 and 2 ). The values of $k^{\prime}$ decreased with the increase in $\left[\mathrm{OH}^{-}\right]$and the plots of $1 / k^{\prime}$ versus $f(\mathrm{OH})\left[\mathrm{OH}^{-}\right]$were line (Figures 3 and $4)$.

3.2. Reaction Mechanism. In aqueous periodate solution, (2)-(4) were detected and the corresponding equilibrium constants at $273.2 \mathrm{~K}$ were determined by Aveston [26] as follows:

$$
\begin{array}{cc}
2 \mathrm{IO}_{4}{ }^{-}+2 \mathrm{OH}^{-} \rightleftharpoons \mathrm{H}_{2} \mathrm{I}_{2} \mathrm{O}_{10}{ }^{4-}, & \log \beta_{1}=15.05, \\
\mathrm{IO}_{4}{ }^{-}+\mathrm{OH}^{-}+\mathrm{H}_{2} \mathrm{O} \rightleftharpoons \mathrm{H}_{3} \mathrm{IO}_{6}{ }^{2-}, & \log \beta_{2}=6.21, \\
\mathrm{IO}_{4}{ }^{-}+2 \mathrm{OH}^{-} \rightleftharpoons \mathrm{H}_{2} \mathrm{IO}_{6}{ }^{3-}, & \log \beta_{3}=8.67 .
\end{array}
$$

The distribution of all species of periodate in alkaline solution can be calculated from (2)-(4). In the $\left[\mathrm{OH}^{-}\right]$range used in this work, the dimer and $\mathrm{IO}_{4}{ }^{-}$species of periodate can be neglected. The main species of periodate are $\mathrm{H}_{2} \mathrm{IO}_{6}{ }^{3-}$

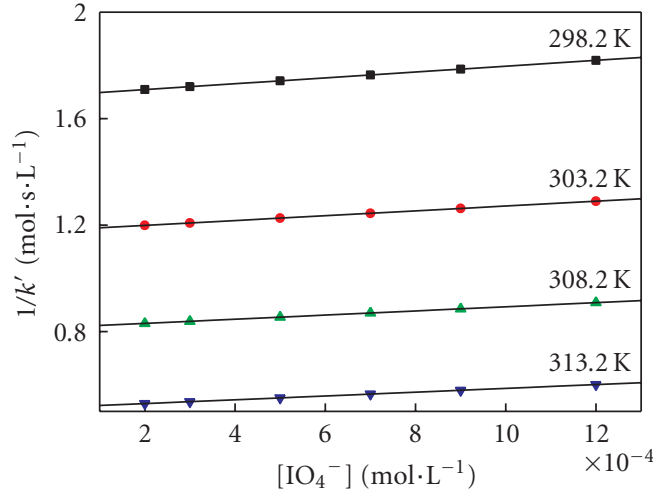

Figure 2: The second-order rate constant, $k^{\prime}$, as a function of the concentration of $\mathrm{IO}_{4}{ }^{-}$at different temperatures for oxidation of alanine.

and $\mathrm{H}_{3} \mathrm{IO}_{6}{ }^{2-}$. Equation (5) can be obtained from (2), (3), (4) as follows:

$$
\begin{aligned}
{\left[\mathrm{H}_{2} \mathrm{IO}_{6}{ }^{3-}\right] } & =\frac{\beta_{3}\left[\mathrm{OH}^{-}\right]^{2}}{1+\beta_{2}\left[\mathrm{OH}^{-}\right]+\beta_{3}\left[\mathrm{OH}^{-}\right]^{2}} \\
{\left[\mathrm{IO}_{4}{ }^{-}\right]_{\mathrm{ex}} } & =f\left(\left[\mathrm{OH}^{-}\right]\right)\left[\mathrm{IO}_{4}^{-}\right]_{\mathrm{ex}},
\end{aligned}
$$

where $\left[\mathrm{IO}_{4}^{-}\right]_{\mathrm{ex}}$ represents the concentration of original overall periodate ion.

From the discussion above, the reaction mechanism was proposed as below:

$$
\begin{aligned}
& {\left[\mathrm{Ag}\left(\mathrm{HIO}_{6}\right)_{2}\right]^{5-}+3 \mathrm{H}_{2} \mathrm{O}} \\
& \stackrel{K_{1}}{\rightleftharpoons}\left[\mathrm{Ag}\left(\mathrm{H}_{2} \mathrm{O}\right)_{2}\left(\mathrm{HIO}_{6}\right)\right]^{-}+\mathrm{H}_{2} \mathrm{IO}_{6}{ }^{3-}+\mathrm{OH}^{-}, \\
& {\left[\mathrm{Ag}\left(\mathrm{H}_{2} \mathrm{O}\right)_{2}\left(\mathrm{HIO}_{6}\right)\right]^{-}+\mathrm{RCH}\left(\mathrm{NH}_{2}\right) \mathrm{COO}^{-}} \\
& \quad \stackrel{K}{\longrightarrow}\left[\mathrm{Ag}\left(\mathrm{H}_{2} \mathrm{O}\right)_{2}\left(\mathrm{HIO}_{6}\right)\left(\mathrm{RCH}\left(\mathrm{NH}_{2}\right) \mathrm{COO}^{-}\right)\right]^{2-},
\end{aligned}
$$


TABLE 2: Thermodynamic activation parameters for the oxidation of leucine and alanine by $\mathrm{Ag}(\mathrm{III})$ complex in alkaline medium.

\begin{tabular}{lccc}
\hline \multicolumn{4}{c}{ Thermodynamic activation parameters } \\
\hline Reaction for oxidation of leucine & & \\
\hline Temperature (K) & $10 \mathrm{k} /\left(\mathrm{M}^{-1} \cdot \mathrm{s}^{-1}\right)$ & \\
298.2 & 2.75 & $\mathrm{Ea} /\left(\mathrm{KJ} \cdot \mathrm{mol}^{-1}\right)$ & $59.34 \pm 4.37$ \\
303.2 & 4.10 & $\triangle H^{\#} /\left(\mathrm{KJ} \cdot \mathrm{mol}^{-1}\right)$ & $56.86 \pm 4.37$ \\
308.2 & 6.54 & $\triangle S^{\#} /\left(\mathrm{J} \cdot \mathrm{K}^{-1} \cdot \mathrm{mol}^{-1}\right)$ & $-64.83 \pm 14.3$ \\
313.2 & 8.40 & $10^{3} \mathrm{~K} /\left(\mathrm{mol}^{-1}\right)^{2}$ & $7.09 \pm 0.42$ \\
\hline Reaction for oxidation of alanine & & & \\
\hline Temperature (K) & $10 \mathrm{k} /\left(\mathrm{M}^{-1} \cdot \mathrm{s}^{-1}\right)$ & $E \mathrm{a} /\left(\mathrm{KJ} \cdot \mathrm{mol}^{-1}\right)$ & $60.95 \pm 3.15$ \\
298.2 & 5.93 & $\triangle H^{\#} /\left(\mathrm{KJ} \cdot \mathrm{mol}^{-1}\right)$ & $58.47 \pm 3.15$ \\
303.2 & 8.47 & $\triangle S^{\#} /\left(\mathrm{J} \cdot \mathrm{K}^{-1} \cdot \mathrm{mol}^{-1}\right)$ & $53.40 \pm 10.31$ \\
308.2 & 12.3 & $10^{3} \mathrm{~K} /\left(\mathrm{mol}^{-1}\right)^{2}$ & $6.44 \pm 0.49$ \\
313.2 & 19.4 &
\end{tabular}

$\mathrm{R}$ means $\left(\mathrm{CH}_{3}\right)_{2} \mathrm{CHCH}_{2}$-for leucine and $\mathrm{H}$-for alanine

$$
\begin{aligned}
& {\left[\mathrm{Ag}\left(\mathrm{H}_{2} \mathrm{O}\right)_{2}\left(\mathrm{HIO}_{6}\right)\left(\mathrm{RCH}\left(\mathrm{NH}_{2}\right) \mathrm{COO}^{-}\right)\right]^{2-}} \\
& \stackrel{\text { fast }}{\longrightarrow} \mathrm{Ag}(\mathrm{I})+\mathrm{RCOCOO}^{-}+\mathrm{H}_{2} \mathrm{IO}_{6}{ }^{3-}+\mathrm{H}_{2} \mathrm{O}+\mathrm{NH}_{3}, \\
& {[\mathrm{Ag}(\mathrm{III})]_{\text {tot }}} \\
& \quad=\left[\mathrm{Ag}\left(\mathrm{OH}^{-}\right)_{2}\left(\mathrm{H}_{2} \mathrm{IO}_{6}\right)_{2}\right]_{\mathrm{e}}{ }^{5-}+\left[\mathrm{Ag}\left(\mathrm{OH}^{-}\right)_{2}\left(\mathrm{HIO}_{6}\right)\right]_{\mathrm{e}}{ }^{3-} .
\end{aligned}
$$

Here "e" and "tot" mean the equilibrium concentration of the all kinds of $\operatorname{Ag}(\mathrm{III})$ complexes and the total concentration of all kinds of $\mathrm{Ag}(\mathrm{III})$ complexes, respectively. The reaction (7) is the rate-determining step, $k$ means the rate-determining step constant, the rate equation can be expressed as below:

$$
\begin{aligned}
\frac{-\mathrm{d}[\mathrm{Ag}(\mathrm{III})]_{\mathrm{T}}}{\mathrm{dt}} & \\
& =k_{\mathrm{obs}} \cdot[\mathrm{Ag}(\mathrm{III})]_{\mathrm{tot}} \\
& =k^{\prime}\left[\mathrm{Ag}\left(\mathrm{H}_{2} \mathrm{O}\right)_{2}\left(\mathrm{HIO}_{6}\right)^{-}\right] \cdot\left[\mathrm{RCH}\left(\mathrm{NH}_{2}\right) \mathrm{COO}^{-}\right] \\
& =\frac{k \mathrm{~K}_{1}[\mathrm{R}][\mathrm{Ag}(\mathrm{III})]_{\mathrm{tot}}}{\mathrm{K}_{1}+\left[\mathrm{H}_{2} \mathrm{IO}_{6}{ }^{3-}\right]\left[\mathrm{OH}^{-}\right]}, \\
k_{\text {obs }}= & \frac{k \mathrm{~K}_{1}[\mathrm{R}]}{\mathrm{K}_{1}+\left[\mathrm{H}_{2} \mathrm{IO}_{6}{ }^{3-}\right]\left[\mathrm{OH}^{-}\right]} .
\end{aligned}
$$

Then substitute (5) for $\left[\mathrm{H}_{2} \mathrm{IO}_{6}{ }^{3-}\right]$ in (10) is as follows:

$$
\begin{aligned}
k_{\mathrm{obs}} & =\frac{k \mathrm{~K}_{1}[\mathrm{R}]}{\mathrm{K}_{1}+f\left(\left[\mathrm{OH}^{-}\right]\right)\left[\mathrm{IO}_{4}^{-}\right]_{\mathrm{ex}}\left[\mathrm{OH}^{-}\right]}, \\
k^{\prime} & =\frac{k \mathrm{~K}_{1}}{\mathrm{~K}_{1}+f\left(\left[\mathrm{OH}^{-}\right]\right)\left[\mathrm{IO}_{4}^{-}\right]_{\mathrm{ex}}\left[\mathrm{OH}^{-}\right]} .
\end{aligned}
$$

From (12), the plot of $1 / k^{\prime}$ versus $f(\mathrm{OH}) \cdot\left[\mathrm{OH}^{-}\right]$is a straight line, and $1 / k^{\prime}$ versus $\left[\mathrm{IO}_{4}^{-}\right]_{\mathrm{ex}}$ is straight line too, which can explain all the experimental phenomena, and the activation parameters according to $k$ are calculated [27] (see Table 2).

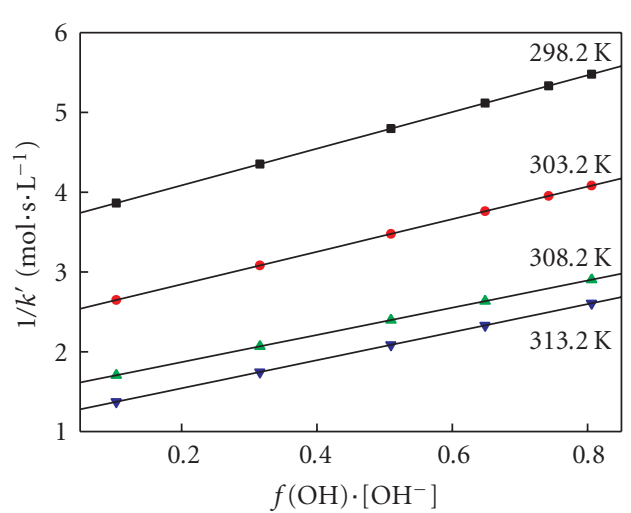

FIGURE 3: The second-order rate constant, $k^{\prime}$, as a function of the concentration of $\mathrm{OH}^{-}$at different temperatures for oxidation of leucine.

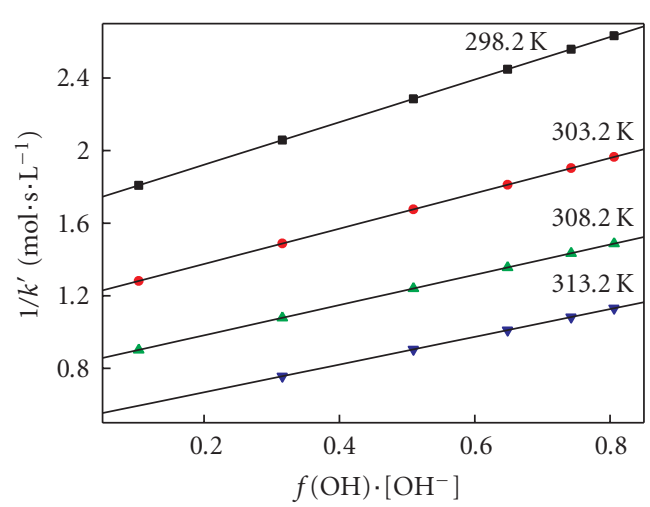

FIgURE 4: The second-order rate constant, $k^{\prime}$, as a function of the concentration of $\mathrm{OH}^{-}$at different temperatures for oxidation of alanine.

\section{Conclusion}

Through the kinetics study, we supposed a simple reaction mechanism, which can explain the reaction very well. Activation parameters and rate determining step constant were calculated from the rate law derived from the proposed 
reaction mechanism. The negative value of $\triangle S^{\#}$ suggested that intermediate complex is more in order than the reactants. The higher rate constant for the rate determining step indicates that the oxidation presumably occurs via innersphere mechanism. The pre-equilibrium constants, $\mathrm{K}_{1}$, are calculated at $298.2 \mathrm{~K}$, which are smaller values. This also shows that rate law from equilibrium hypothesis is suitable for the reaction mechanism.

\section{References}

[1] J.-H. Shan, S.-Y. Huo, S.-G. Shen, H.-W. Sun, and A.-Z. Wang, "Kinetics and mechanism of oxidation of glutamic acid by dihydroxydipriodatoargentate (III) with spectrophotometry in alkaline medium," Chemical Journal of Chinese Universities, vol. 26, no. 4, pp. 706-709, 2005.

[2] P. Jaya Prakash Rao, B. Sethuram, and T. N. Rao, "Kinetics of oxidative deamination of some amino acids by diperiodatoargentate(III) in alkaline medium," Reaction Kinetics and Catalysis Letters, vol. 29, no. 1, pp. 289-296, 1985.

[3] J.-H. Shan, S.-M. Li, S.-Y. Huo, S.-G. Shen, and H.-W. Sun, "Kinetics and mechanism of oxidation of some diols by dihydroxydiperiodatoargentate(III) in alkaline medium," Chinese Journal of Chemistry, vol. 24, no. 4, pp. 478-480, 2006.

[4] J.-H. Shan, S.-M. Li, S.-Y. Huo, W.-J. Zhao, S.-G. Shen, and H.-W. Sun, "Kinetics of oxidation of 1,4-butylene glycol by dihydroxydiperiodatoargentate(III) in alkaline medium," Journal of Chemical Research, no. 7, pp. 424-425, 2006.

[5] P. Bandyopadhyay and S. Mukhopadhyay, "Kinetics of oxidation of hydroxylamine by [ethylenebis(biguanide)] silver(III) in aqueous media," Polyhedron, vol. 21, no. 19, pp. 1893-1898, 2002.

[6] A. Das and S. Mukhopadhyay, "Kinetics of oxidation of glyoxylic acid by [ethylenebis(biguanide)] silver(III) in aqueous media," Polyhedron, vol. 23, no. 5, pp. 895-901, 2004.

[7] A. Balikungeri, M. Pelletier, and D. Monnier, "Contribution to the study of the complexes bis(dihydrogen tellurato)cuprate(III) and argentate(III), bis(hydrogen periodato)cuprate(III) and argentate(III)," Inorganica Chimica Acta, vol. 22, pp. 7-14, 1977.

[8] L. J. Kirschenbaum, J. H. Ambrus, and G. Atkinson, "Kinetics of silver(III) complexation by periodate and tellurate ions," Inorganic Chemistry, vol. 12, no. 12, pp. 2832-2837, 1973.

[9] K. K. Sen Gupta, B. K. Nandy, and S. Sen Gupta, "Kinetics of oxidation of some aryl alcohols by bis(dihydridotellurato)cuprate(III) and -argentate(III) in alkaline medium," Journal of Organic Chemistry, vol. 59, no. 4, pp. 858-863, 1994.

[10] S. Chandra and K. L. Yadava, "Oxidation of some sugars with copper(III)," Talanta, vol. 15, no. 3, pp. 349-352, 1968.

[11] P. K. Jaiswal and K. L. Yadava, "Silver (III) as an oxidative titrant determination of some sugars, carboxylic acids and inorganic ions," Talanta, vol. 17, no. 3, pp. 236-238, 1970.

[12] J.-H. Shan, S.-Y. Huo, S.-G. Shen, and H.-W. Sun, "Kinetics and mechanism of the oxidation of polyhydric alcohols by dihydroxyditelluratoargentate(III) in alkaline medium," Journal of the Serbian Chemical Society, vol. 70, no. 4, pp. 585592, 2005.

[13] R. Pascual, M. A. Herraez, and E. Calle, "Kinetics and mechanism of the oxidation of proline by periodate," Canadian Journal of Chemistry, vol. 67, no. 4, pp. 634-638, 1989.
[14] B. T. Gowda and P. J. M. Rao, "Kinetics and mechanism of oxidation of amino acids by dichloramine T," Bulletin of the Chemical Society of Japan, vol. 62, no. 10, pp. 3303-3310, 1989.

[15] Y. R. Katre, A. K. Singh, S. Patil, and G. K. Joshi, "Kinetic studies on the mechanism of oxidation of DL-serine by chloramine-T in micellar system," Oxidation Communications, vol. 29, no. 1, pp. 129-136, 2006.

[16] Y. R. Katre, A. K. Singh, G. K. Joshi, and S. Patil, “Oxidation of DL-valine and DL-alanine by sodium N-chloro-4-methyl benzene sulphonamide in micellar medium. A relative kinetic study," Oxidation Communications, vol. 29, no. 1, pp. 137-146, 2006.

[17] N. Nalwaya, A. Jain, and B. L. Hiran, "Oxidation of some $\alpha$ amino acids by pyridinium bromochromate in an aquo-acetic acid medium - a kinetic and mechanistic study," Kinetics and Catalysis, vol. 45, no. 3, pp. 345-350, 2004.

[18] R. M. Rodriguez, J. D. Andres, E. B. Brillas, J. A. Garrido, and J. P. Benito, "The autocatalytic permanganate oxidation of Lthreonine," New Journal of Chemistry, vol. 12, no. 2-3, pp. 143146, 1988.

[19] R. T. Mahesh, M. B. Bellakki, and S. T. Nandibewoor, "Kinetics and mechanism of oxidation of L-proline by heptavalent manganese: a free radical intervention and decarboxylation," Journal of Chemical Research, no. 1, pp. 13-17, 2005.

[20] S. A. Chimatadar, A. K. Kini, and S. T. Nandibewoor, "Kinetic and mechanistic study of oxidation of L-aspartic acid by diperiodatocuprate(III) in aqueous alkaline medium," Oxidation Communications, vol. 29, no. 1, pp. 147-157, 2006.

[21] R. M. Mulla, H. M. Gurubasavaraj, and S. T. Nandibewoor, "Kinetics and mechanism of oxidative degradation of Lproline by alkaline diperiodatonickelate(IV) - a free radical intervention and decarboxylation," Polish Journal of Chemistry, vol. 77, no. 12, pp. 1833-1840, 2003.

[22] V. Soni, R. S. Sindal, and R. N. Mehrotra, "Kinetics of oxidation of l-histidine by tetrachloroaurate(III) ion in perchloric acid solution," Polyhedron, vol. 24, no. 10, pp. 1167-1174, 2005.

[23] R. Pascual and M. A. Herráez, "The mechanism of the oxidative deamination and decarboxylation of serine and threonine by periodate in acid medium," Canadian Journal of Chemistry, vol. 63, no. 9, pp. 2349-2353, 1985.

[24] T.-S. Shi, J.-T. He, T.-H. Ding, and A.-Z. Wang, "Studies of unusual oxidation states of transition metals III-kinetics and mechanism of oxidation of triethanolamine by diperiodatoargenate(III) ion in aqueous alkaline medium," International Journal of Chemical Kinetics, vol. 23, no. 9, pp. 815-823, 1991.

[25] F. Feigl, Spot Tests in Organic Analysis, Elsevier, New York, NY, USA, 1956.

[26] J. Aveston, "Hydrolysis of potassium periodate: ultracentrifugation, potentiometric titration, and Raman spectra," Journal of Chemical Society A, pp. 273-275, 1969.

[27] J. H. Shan and T. Y. Liu, "Kinetics and mechanism of substitution reactions of bis(N,N-diethyldithiocarbamato) alkylxanthatocobalt(III) with dipropylamine and di-n-butylamine in methanol," Acta Chimica Sinica, vol. 52, no. 11, pp. 1140-1144, 1994. 


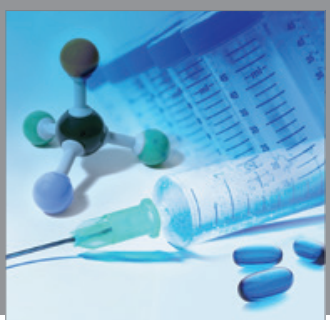

International Journal of

Medicinal Chemistry

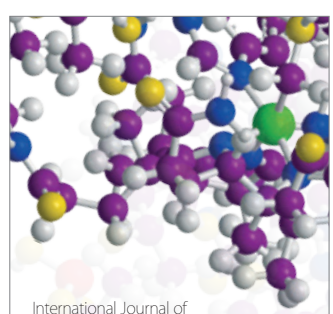

Carbohydrate Chemistry

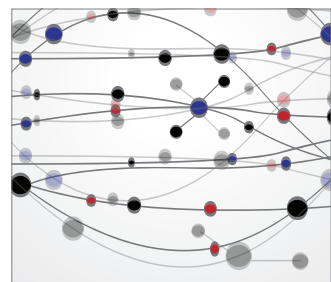

The Scientific World Journal
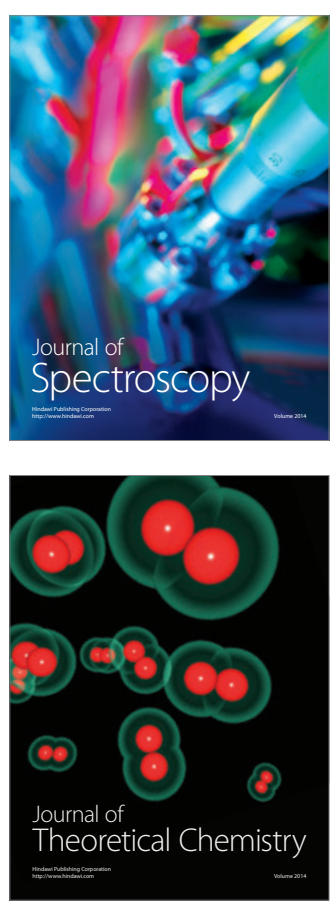
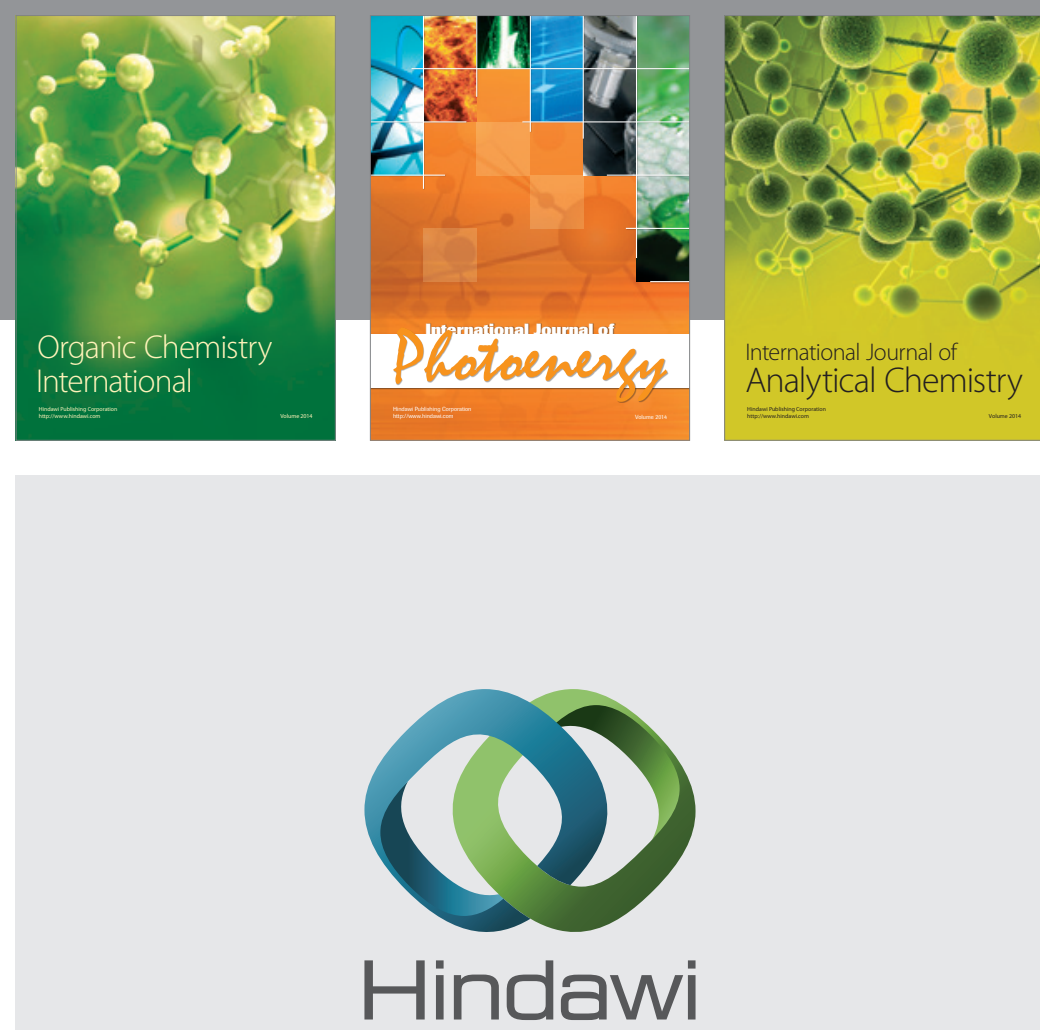

Submit your manuscripts at

http://www.hindawi.com
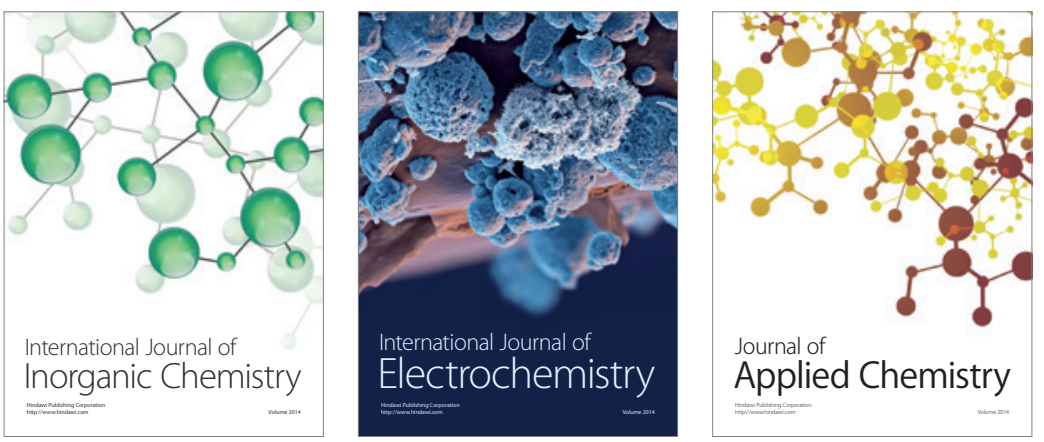

Journal of

Applied Chemistry
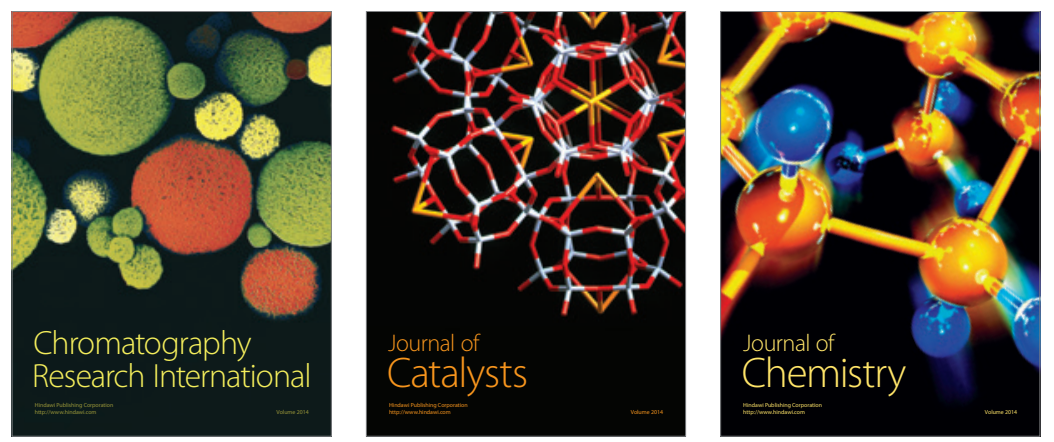
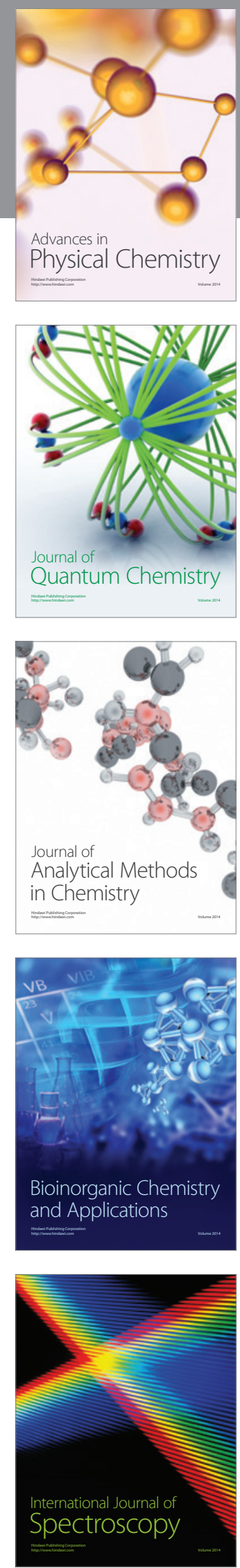